\title{
Research on Green Collaborative Innovation Mechanism of Cloud Manufacturing Enterprises under Government Supervision
}

\author{
Jiaqi Zhai $\mathbb{D}^{1},{ }^{1}$ Xinliang Xu $\mathbb{D},^{2}$ Jianzhong Xu $\mathbb{D}^{1},{ }^{1}$ and Xichen Lyu $\mathbb{D}^{3}$ \\ ${ }^{1}$ School of Economics and Management, Harbin Engineering University, Harbin, Heilongjiang 150001, China \\ ${ }^{2}$ School of Economics and Management, Northeast Agricultural University, Harbin, Heilongjiang 150030, China \\ ${ }^{3}$ School of Economics and Management, Harbin University of Science and Technology, Harbin, Heilongjiang 150080, China \\ Correspondence should be addressed to Xinliang Xu; xuxinliang@neau.edu.cn
}

Received 14 September 2020; Revised 27 February 2021; Accepted 5 March 2021; Published 10 April 2021

Academic Editor: Francisco Rossomando

Copyright (C) 2021 Jiaqi Zhai et al. This is an open access article distributed under the Creative Commons Attribution License, which permits unrestricted use, distribution, and reproduction in any medium, provided the original work is properly cited.

With the rapid development of information technology, the sharing economy based on "Internet plus" cloud platforms has become a new collaborative innovation mode and a hot topic in recent years. Considering that government regulation restricts green innovation cooperation among cloud manufacturing enterprises, an evolutionary game model involving the government and cloud manufacturing enterprises A and B with potential differences in their technology knowledge is established using evolutionary game theory. A replication dynamic equation is established, the evolutionarily stable equilibrium strategy of the three parties is analysed, and the key factors affecting the cooperative selection strategy of the government and cloud manufacturing enterprises are discussed through a MATLAB-based numerical simulation. This research shows that when governmental incentives and punishments, the platform load capacity, the trust between enterprises, the technology loss coefficient, and the informatization degree are increased, the government will tend to choose supervision, and cloud manufacturing enterprises A and B will tend to choose the "collaborative innovation" strategy. These results provide a scientific basis suggesting that the government should not only formulate rules and regulations for cloud manufacturing enterprises but also promote green collaborative innovation among such enterprises and enhance their core competitiveness.

\section{Introduction}

With the rapid development of information technology, Internet-based strategies are accelerating worldwide. As a new collaborative innovation mode, the cooperation and sharing economy based on "Internet+" is very popular [1]. According to a report released by Credit Suisse, the global market value of the sharing economy will reach $\$ 335$ billion by 2025 [2]. As a rapidly developing country, China has achieved great progress in innovation and entrepreneurship in the field of the sharing economy and has become an innovator and a leader of the global sharing economy. With the deepening of globalization and regional integration, various regions have produced public environmental pollution problems to different degrees and have become the focal points of local governments. Therefore, under the new era of global sustainable development and China's
"Internet+" development, green innovation has become a general consensus in the information manufacturing industry. Furthermore, after the integration of cloud computing, the Internet of things (IoT), and other emerging technologies, the "cloud manufacturing" mode will accelerate this development [3]. Cloud manufacturing is a new manufacturing mode and technological means of accelerating the realization of "agile manufacturing," "serviceoriented manufacturing," and "green manufacturing" and "created in China" in the manufacturing industry. Cloud manufacturing allows the information and resources of manufacturing enterprises to seamlessly connect and promotes the development of the manufacturing industry in agile, service-oriented, green, and intelligent directions [4]. Cloud manufacturing enables manufacturing resources to be highly shared through cloud services, greatly changing the traditional production mode. Enterprises can build virtual 
enterprise alliances through cloud manufacturing platforms (CMPs) and share green manufacturing resources to improve the speed of technological innovation and enterprise performance [5]. Therefore, it is particularly important to accelerate the green technology innovation of cloud manufacturing enterprises. However, enterprises commonly learn from each other, use each other's core resources, and protect their own technological advantages [6]. Enterprises not only choose green technology innovation cooperation in the cloud manufacturing environment but also play interest games in cooperation, posing new challenges to the government's supervision mode under the traditional economic mode $[7,8]$. What kind of regulatory concept should the government establish, and what kind of system of punishments and rewards should be adopted to promote green collaborative innovation among cloud manufacturing enterprises? The green innovation cooperation of cloud platforms represents a typical tripartite evolutionary game between the government and cloud manufacturing enterprises and requires a comprehensive consideration of the government's regulatory mechanism and the choice of cooperation strategies of cloud manufacturing enterprises to maximize the expected interests of all parties [9].

Therefore, this study establishes an evolutionary game model between the government and cloud manufacturing enterprises and studies the cooperative behaviour choices of cloud manufacturing enterprises under the government supervision mechanism. The main objectives of this paper are as follows:

(1) This paper aims to analyse the evolutionary trend of the dynamic cooperation process of enterprise green innovation in the cloud manufacturing environment and measure the influence of various factors on the equilibrium strategy in different situations.

(2) This paper aims to analyse the impact of government regulation on cloud manufacturing enterprises' green cooperative innovation behaviour and determine how cloud manufacturing enterprises choose the green cooperative innovation behaviour strategy to optimize the government regulation mechanism and promote green innovation cooperation between enterprises.

The remainder of this paper is structured as follows. Section 2 reviews the relevant literature. In Section 3, the research problems are described, and the basic parameters and related assumptions of the theoretical model are proposed. In Section 4, the evolutionary game model of the green collaborative innovation of cloud manufacturing enterprises is constructed, the equilibrium stable state of the model is determined, and its stability is analysed under the two states of government supervision and government nonsupervision. In Section 5, a numerical simulation is conducted to compare and analyse the influence of different parameter changes on the evolutionary results. In Section 6, the conclusions and recommendations are provided.

\section{Literature Review}

This section is divided into four main parts. The first part introduces the concept and project of cloud manufacturing. The second part introduces the definition of green technology innovation cooperation and its application in enterprise competition. The third part introduces the impact of government regulation on green innovation. The fourth part introduces the main research content and innovation of this paper. This paper reviews and summarizes the relevant literature, which can be divided into the following three categories: (1) the concept and application of cloud manufacturing enterprises; (2) the government's role in green collaborative innovation; and (3) evolutionary game theory.

2.1. Cloud Manufacturing Concept and Project. In recent years, the cloud manufacturing service model has been proposed to achieve comprehensive sharing and collaboration of manufacturing resources and capabilities and improve the utilization of manufacturing resources. Since the proposal of the concept and architecture of cloud manufacturing, the typical characteristics of cloud manufacturing and the architecture and key technologies of cloud platforms have also been proposed [10-12]. In recent years, based on the innovative practice of cloud manufacturing and the theory of the sharing economy, many scholars have noted that cloud manufacturing links the manufacturing resources of enterprises using industrial Internet of things (IIOT) technology, which forms cloud manufacturing resources that can be shared and utilized through resource management. CMPs will integrate cloud manufacturing to meet the customized processing and service requirements of customers, further optimize the configuration of grid cloud manufacturing resources, and complete the intelligent manufacturing process based on knowledge $[13,14]$. After a detailed classification of the resources under the cloud manufacturing mode, the description model of manufacturing capability (DMMC) can be used to describe CMPs' manufacturing capability [15]. In research concerning the architecture and key technologies of cloud manufacturing, based on matching market theory [16], we can design a bilateral matching mechanism of CMP resources, solve the stability problem posed by the matching and scheduling of cloud manufacturing resources, and then design a bilateral matching mechanism for the decision making of cloud manufacturing participants characterized by bounded rationality $[17,18]$. The processes of summarizing service matching, evaluation, selection and configuration [19], big data analysis [20], and bilevel programming and game theory $[21,22]$ are some effective means to achieve efficient resource allocation via CMPs.

\subsection{The Government's Role in Green Collaborative Innovation.}

Green innovation refers to business processes that aim to save energy, reduce consumption and emissions, improve environmental quality, and constantly realize the economic benefits of innovation. To date, many scholars have found 
that the government plays a significant role in guiding and standardizing enterprises' green innovation. The relevant domestic and international research mainly focuses on the incentives and punishments of the government $[23,24]$. In the process of promoting green technology innovation, government policies play an irreplaceable role regardless of whether these policies provide incentive support or punishment for enterprises. For example, regarding government policy support, different stakeholders will place pressure on enterprises' operational processes, including cooperative enterprises, government agencies, and nongovernmental organizations [25]. Governmental environmental regulation will promote green technology innovation and diffusion through the innovation compensation effect [26]. Specific government regulatory policies deliver clear and standard information to green innovation enterprises and guide enterprises to comply with regulatory standards [27]. For example, by studying the long-term positive impact of electricity prices on renewable energy technology innovation, we can determine the influence of government price regulation mechanisms on green technology innovation [28]. The government can also use subsidies to provide a positive incentive mechanism for suppliers. The three modes of no subsidies, subsidies to manufacturers, and subsidies to consumers can have different degrees of impact on enterprise decision making and income $[29,30]$. Based on the research results, we can further consider enterprises' strategic behaviour. Subsidies to manufacturers can be subdivided into different aspects, such as the green degree of the subsidy object (i.e., the environmental friendliness of all an enterprise's production and operational activities) and the influence of subsidies on production or R\&D costs [31]. Government subsidies can increase the revenue of green enterprises and the profit of the supply chain system regardless of the mode.

Regarding governmental punishment mechanisms, the "Porter hypothesis" posits that environmental regulation can stimulate enterprises to conduct green technology innovation and improve their competitive advantage [32]. Based on the Porter hypothesis, subsequent scholars have examined the impact of environmental regulation on enterprises from different perspectives, including the relationship between environmental regulation and enterprise competitiveness [33], innovation [34], productivity [35, 36], and labour demand [37]. Reasonable punishment can promote technological cooperation between enterprises, and negotiation punishment can produce a better cooperation effect than independent punishment [38]. Strict government environmental control and advocacy of green environmental behaviour help enterprises adopt environmental innovation behaviour and effectively achieve a win-win situation in terms of environmental and economic benefits [39]. Strong government punishment intervention is helpful in formulating reasonable green supply chain pricing and green level decision making and effectively stimulating the development of green products [40]. Furthermore, the establishment of a green supply chain contract and a government punishment mechanism can effectively solve the problem of "free riding" behaviour by suppliers and manufacturers in green innovation investment [41].

As mentioned above, several studies have examined the role of producers and recyclers in green innovation, as well as the impact of government policies. However, few have linked producers' green innovation to cloud manufacturing. Due to this gap in the literature, we focus on cloud manufacturing enterprises' green innovation cooperation process to explore its evolutionary game relationships under the supervision of government and cloud platforms.

2.3. Evolutionary Game Theory. Evolutionary game theory was originally proposed in the field of biology. In this method, individuals with limited rationality are defined as those who do not have the ability to accurately calculate their payoff and make the best decisions. These individuals achieve dynamic equilibrium through imitation, learning, mutation, and other processes and finally reach the ESS of the system. This theory has also been widely applied in economic management and operations [42].

Many studies have used evolutionary game theory to investigate the dynamic behaviours of manufacturing enterprises [43]. Zhao and Bai use evolutionary game theory to investigate the strategies used by producers and recyclers and explore their evolutionary behaviours under two policies [44]. Chen and $\mathrm{Hu}$ construct an evolutionary game model to study manufacturing enterprises' behaviour under various strategy combinations of carbon taxes and subsidies [45]. Li et al. construct a tripartite evolutionary game model of government, enterprises, and financial institutions and analyse the evolutionary process of the interaction between government regulation and manufacturing enterprises' green innovation [46]. Some scholars have also studied the impact of government subsidies on the independent R\&D and technology introduction strategies of new energy enterprises by constructing an evolutionary game model [47].

Based on this literature review, there are abundant research studies that use evolutionary game theory to investigate participants' dynamic behaviours under government policy. However, existing studies ignore the interaction among the government, cloud platforms, and enterprises, and few have studied the dynamic evolution of strategy selection among cloud manufacturing enterprises in green innovation cooperation. In practice, green innovation is a continuous and dynamic process that directly depends on enterprise cooperation income, government policy, platform punishment, and other key factors. In the real world, it is difficult for participants to be entirely rational, so we assume bounded rationality among cloud manufacturing enterprises and investigate the guiding role of government and cloud platforms in green innovation cooperation.

In summary, the innovations of this paper are as follows. Firstly, a tripartite evolutionary game model is developed to describe the dynamic behaviour and interaction mechanism among government, cloud manufacturing enterprise $\mathrm{A}$, and cloud manufacturing enterprise B (there is technological distance between enterprises) and explore green innovation cooperation from a new perspective. Secondly, this paper 
revises some conclusions on static games and analyses the stable equilibrium strategy of evolutionary games and the gradual stability of innovation diffusion. Moreover, compared with a traditional static game model, our approach can better reveal the dynamic evolutionary process of the game agents with a gradual strategy selection. Finally, as important members of the green innovation process, the government and cloud platforms play important regulatory roles. This paper provides a scientific basis for the decision making of the government and cloud manufacturing enterprises, which helps promote the green collaborative innovation of cloud manufacturing enterprises and enhance the core competitiveness of enterprises.

\section{Problem Description and Basic Assumptions}

3.1. Problem Description. Green innovation cooperation is a complicated and systematic project involving multiple interests, and its action mechanism is complex and far-reaching. In the evolutionary process of green innovation, cloud manufacturing enterprises will adjust their green innovation cooperation behaviour by considering the benefits and costs. The government guides and coordinates the cooperation of cloud manufacturing enterprises through policies, laws, and economic means. Green innovation cooperation is affected by the internal and external host and guest environment of cloud manufacturing enterprises $\mathrm{A}$ and $\mathrm{B}$ and the government innovation system. We believe that green innovation cooperation is a dynamic bargaining process that can be regarded as a dynamic equilibrium. Therefore, this paper views the government and cloud manufacturing enterprises $\mathrm{A}$ and $\mathrm{B}$ as participants in an evolutionary game, and each of the three parties will adopt corresponding strategies to address the strategies of the other two parties. In the process of green innovation, game players characterized by bounded rationality will make corresponding behavioural decisions to maximize their interests.

\subsection{Basic Assumptions}

Hypothesis 1. The main bodies involved in green innovation are the government and cloud manufacturing enterprises $\mathrm{A}$ and B. Cloud manufacturing enterprise A has technology advantages and resource advantages, and its technological level is high; cloud manufacturing enterprise $B$ has an average technological level. The three parties are characterized by bounded rationality, and the parties' information is asymmetric.

Hypothesis 2. Cloud manufacturing enterprises A and B and the government have two behavioural strategies. Cloud manufacturing enterprises $\mathrm{A}$ and $\mathrm{B}$ have the two strategies of "collaborative innovation" and "noncollaborative innovation." In turn, the government should actively guide the cloud manufacturing enterprises' green technology innovation activities, punish the noncooperative partners of cooperative enterprises or not adopt any regulatory policies, i.e., "supervision" and "nonsupervision." In the process of enterprise development, the involved parties can form a virtuous cycle in the game process and effectively promote green collaborative innovation via CMPs only when the government and enterprises $\mathrm{A}$ and $\mathrm{B}$ find a benign equilibrium mechanism.

Hypothesis 3. The probability of the government adopting the supervision strategy is $x(0 \leq x \leq 1)$, and the probability of the government adopting the nonsupervision strategy is $1-x$. The probability of cloud manufacturing enterprise A adopting the collaborative innovation strategy is $y(0 \leq y \leq 1)$, and the probability of manufacturing enterprise A adopting the noncollaborative innovation strategy is $1-y$. The probability of cloud manufacturing enterprise $\mathrm{B}$ adopting the "sharing" strategy is $z(0 \leq z \leq 1)$, and the probability of cloud manufacturing enterprise B adopting the "nonsharing" strategy is $1-z$.

Hypothesis 4. When enterprises A and B via the CMP both choose the nonsharing strategy, i.e., the two sides do not share technology, the basic benefits of enterprises A and B are $\pi_{1}$ and $\pi_{2}$, respectively, and the amounts of heterogeneous technologies owned by both parties are $a_{1}$ and $a_{2}$, where $a_{1}>a_{2}$. Furthermore, because enterprise $\mathrm{A}$ has technology and resource advantages and its technological level is high, enterprise $B$ needs to pay additional access cost $C_{0}$ when entering the CMP.

Hypothesis 5. When enterprises A and B via the CMP choose the "sharing" strategy, i.e., both sides share technology, the amount of technology they share is related to the government's incentive and the degree of trust that both sides have in each other, and the amounts of technology shared by enterprises $\mathrm{A}$ and $\mathrm{B}$ are $\lambda \times \theta \times a_{1}$ and $\lambda \times \theta \times a_{2}\left(a_{1}>a_{2}\right)$, respectively. Furthermore, when both enterprises are connected to the CMP, they create value due to the collaborative benefits of resource sharing. This benefit is basically related to the enterprises. The benefits of synergy can be expressed as $R_{1}^{\omega}$ and $R_{2}^{\omega}$, and their expressions are as follows:

$$
\begin{aligned}
& R_{1}^{\omega}=\omega_{1} \times \pi_{1}, \\
& R_{2}^{\omega}=\omega_{2} \times \pi_{2},
\end{aligned}
$$

where $\omega_{1}$ and $\omega_{2}$ are the synergy profit coefficients of enterprises $\mathrm{A}$ and $\mathrm{B}$ in the cloud manufacturing platform, respectively.

Hypothesis 6. When both enterprises $\mathrm{A}$ and $\mathrm{B}$ are connected to the CMP, they will obtain resource conversion benefits. This part of the revenue is directly related to the enterprises' R\&D level and innovation ability. We denote the conversion benefit coefficient as $r_{1}$ and introduce the conversion benefit factor as $A_{i}-\left(\theta a_{i}\right)^{-r_{i}}$. Here, the conversion benefit factor introduced by the resource conversion of the CMP is a nonlinear function of manufacturing resource sharing $\left(\theta a_{i}\right)$. As the actual shareable manufacturing resources $\left(\theta a_{i}\right)$ increase, the result of the conversion benefit factor correspondingly increases. However, when the amount of the shareable manufacturing resources increases to a certain extent, the expected benefit factor introduced by resource 
conversion will tend towards saturation point A, i.e., it will reach the maximum value in theory. According to Samaddar's innovation performance theory, the innovation performance equation of S\&T resource capitalization is formed and can be used to evaluate the utilization efficiency of enterprises sharing platform resources. Therefore, the resource conversion benefits of enterprises $\mathrm{A}$ and $\mathrm{B}$ are $R_{1}^{U}$ and $R_{2}^{U}$, respectively, which can be expressed as follows:

$$
\begin{aligned}
& R_{1}^{U}=A_{1}-\left(\theta \times a_{1}\right)^{-r_{1}}, \\
& R_{2}^{U}=A_{2}-\left(\theta \times a_{2}\right)^{-r_{2}} .
\end{aligned}
$$

Since the resources shared by the enterprises are mainly core technological advantages, such as various types of professional knowledge and process data, once open and shared, enterprises A and B will also reap benefits from informatization, and their informatization benefit coefficient is $I$. Thus, the informatization benefits of enterprises A and B are $R_{1}^{I}$ and $R_{2}^{I}$, respectively, which can be expressed as follows:

$$
\begin{aligned}
& R_{1}^{I}=I \times \theta \times a_{1}, \\
& R_{2}^{I}=I \times \theta \times a_{2} .
\end{aligned}
$$

Additionally, the resources shared by the enterprises need to be identified and accessed by the IoT and information physical system; thus, the enterprises need to pay a channel cost. The channel cost coefficient is $C$, and the channel cost is $R_{1}^{C}$ and $R_{2}^{C}$, which can be expressed as follows:

$$
\begin{aligned}
& R_{1}^{c}=C \times \theta \times a_{1}, \\
& R_{2}^{c}=C \times \theta \times a_{2} .
\end{aligned}
$$

Moreover, since the resources shared by the enterprises are mainly core technological advantages, such as various types of professional knowledge and process data, once sharing is open, if one enterprise does not share in the cooperation, the other enterprise will bear the risk of technological loss, and the risk coefficient of technological loss is $T$. We denote the cost of the technological loss of enterprises $\mathrm{A}$ and $\mathrm{B}$ as $R_{1}^{T}$ and $R_{2}^{T}$, respectively, which can be expressed as follows:

$$
\begin{aligned}
& R_{1}^{T}=T \times \theta \times a_{1}, \\
& R_{2}^{T}=T \times \theta \times a_{2} .
\end{aligned}
$$

Hypothesis 7. When the government chooses the supervision strategy, it will provide incentives to enterprises that choose the sharing strategy. We denote the government incentive coefficient as $\lambda$. The government incentive obtained by enterprises $\mathrm{A}$ and $\mathrm{B}$ can be denoted as $R_{1}^{L}$ and $R_{2}^{L}$, respectively, which can be expressed as follows:

$$
\begin{aligned}
& R_{1}^{L}=\lambda \times \theta \times a_{1}, \\
& R_{2}^{L}=\lambda \times \theta \times a_{2} .
\end{aligned}
$$

Moreover, if one enterprise chooses the sharing strategy, the government will punish the nonsharing party $K$, and the nonsharing party will need to bear penalty cost $R_{1}^{K}$ and $R_{2}^{K}$, which depends on the enterprise's risk aversion. The greater the degree of risk aversion of the nonsharing party is, the greater the punishment that will be imposed on the nonsharing party. The degree of risk aversion of enterprises $\mathrm{A}$ and $\mathrm{B}$ is denoted as $\mu_{1}$ and $\mu_{2}\left(\mu_{2}>\mu_{1}\right)$, respectively. Therefore, enterprises $\mathrm{A}$ and $\mathrm{B}$ can be expressed as follows:

$$
\begin{aligned}
& R_{1}^{z}=\mu_{1} \times K, \\
& R_{2}^{z}=\mu_{2} \times K .
\end{aligned}
$$

Moreover, if both enterprises choose the sharing strategy, the government will obtain additional social benefits, which are denoted as $\pi_{0}$. In contrast, if either of the two enterprises chooses the nonsharing strategy, the government will suffer losses $S$. The above parameters and notations of the variables in the hypotheses are shown in Table 1.

\section{Model Construction and Analysis}

4.1. Model Construction. Based on the model assumptions above and the strategies that the government, enterprise $\mathrm{A}$, and enterprise $\mathrm{B}$ can choose, there are 8 kinds of game strategy combinations among the three parties as follows: $\left(U_{G 1}, U_{A 1}, U_{B 1}\right), \quad\left(U_{G 1}, U_{A 2}, U_{B 1}\right), \quad\left(U_{G 1}, U_{A 1}, U_{B 2}\right)$, $\left(U_{G 1}, U_{A 2}, U_{B 2}\right), \quad\left(U_{G 2}, U_{A 1}, U_{B 1}\right), \quad\left(U_{G 2}, U_{A 2}, U_{B 1}\right)$, $\left(U_{G 2}, U_{A 1}, U_{B 2}\right)$, and $\left(U_{G 2}, U_{A 2}, U_{B 2}\right)$. Therefore, the tripartite game matrix and payment matrix of the government, enterprise $A$, and enterprise $B$ can be obtained as listed in Tables 2 and 3.

\subsection{Replication Dynamic Equation of the Game Model}

4.2.1. Government's Replication Dynamic Equation. According to evolutionary game theory and the game payment matrix, the average expected return and replication dynamic equations of the government, enterprise $A$, and enterprise B are expressed. The expected benefits of green innovation for the government from supervising the CMP are as follows:

$$
\begin{aligned}
U_{G 1} & =y z\left(\pi_{0}-R_{1}^{L}-R_{2}^{L}\right)+y(1-z)\left(R_{2}^{K}-R_{1}^{L}-S\right)+(1-y) z\left(R_{1}^{K}-R_{2}^{L}-S\right)+(1-y)(1-z)\left(R_{1}^{K}+R_{2}^{K}-S\right) \\
& =y z\left(\pi_{0}+S\right)-y\left(R_{1}^{L}+R_{1}^{K}\right)-z\left(R_{2}^{L}+R_{2}^{K}\right)+\left(R_{1}^{K}+R_{2}^{K}-S\right) .
\end{aligned}
$$


TABLE 1: Related parameter symbols and their meanings.

\begin{tabular}{lc}
\hline Parameter symbol & Meaning \\
\hline$x, 1-x$ & Probability of government supervision or nonsupervision \\
$y, 1-y$ & Probability of enterprise A sharing or not sharing \\
$z, 1-z$ & Probability of enterprise B sharing or not sharing \\
$\pi_{1}, \pi_{2}$ & Basic income of enterprises A and B \\
$a_{1}, a_{2}$ & Heterogeneous technology quantity owned by enterprises A and B \\
$\omega_{1}, \omega_{2}$ & Synergy profit coefficient of enterprises A and B \\
$r_{1}, r_{2}$ & Conversion benefit coefficient of enterprises A and B \\
$A_{1}, A_{2}$ & Saturation point of expected benefits of enterprises A and B \\
$\mu_{1}, \mu_{2}$ & Risk aversion of enterprises A and B \\
$C_{0}$ & Entry costs \\
$\lambda$ & Government's incentive coefficient \\
$\theta$ & Trust between enterprises A and B \\
$I$ & Information efficiency coefficient \\
$C$ & Channel cost coefficient \\
$T$ & Technical loss cost coefficient \\
$K$ & Penalty cost \\
$\pi_{0}, \pi_{3}$ & Additional social benefits of government supervision and nonsupervision \\
$S$ & Government losses \\
\hline
\end{tabular}

TABLE 2: Tripartite game matrix of government and enterprises A and B.

\begin{tabular}{lcccc}
\hline & \multicolumn{2}{c}{ Government supervision $(x)$} & \multicolumn{2}{c}{ Nonsupervision $(1-x)$} \\
& $\begin{array}{c}\text { Enterprise A shares } \\
(y)\end{array}$ & $\begin{array}{c}\text { Enterprise A does not share } \\
(1-y)\end{array}$ & $\begin{array}{c}\text { Enterprise B shares } \\
\text { Enterprise B does not share } \\
(z)\end{array}$ & $(1-z)$ \\
\hline $\begin{array}{l}\text { Enterprise B shares }(z) \\
\text { Enterprise B does not share } \\
(1-z)\end{array}$ & $\left(U_{G 1}, U_{A 1}, U_{B 1}\right)$ & $\left(U_{G 1}, U_{A 2}, U_{B 1}\right)$ & $\left(U_{G 2}, U_{A 1}, U_{B 1}\right)$ & $\left(U_{G 2}, U_{A 2}, U_{B 1}\right)$ \\
\hline
\end{tabular}

TABLE 3: Tripartite game payment matrix.

\begin{tabular}{lccc}
\hline Strategy combination & Government & Enterprise A & Enterprise B \\
\hline$\left(U_{G 1}, U_{A 1}, U_{B 1}\right)$ & $\pi_{0}-R_{1}^{L}-R_{2}^{L}$ & $\pi_{1}+R_{1}^{L}+R_{1}^{U}+R_{1}^{\omega}+R_{1}^{I}-R_{1}^{c}$ & $\pi_{2}+R_{2}^{L}+R_{2}^{U}+R_{2}^{\omega}+R_{2}^{I}-R_{2}^{c}-C_{0}$ \\
$\left(U_{G 1}, U_{A 2}, U_{B 1}\right)$ & $R_{1}^{K}-R_{2}^{L}-S$ & $\pi_{1}-R_{1}^{K}+R_{2}^{T}$ & $\pi_{2}+R_{2}^{L}+R_{2}^{I}-R_{2}^{c}-R_{2}^{T}-C_{0}$ \\
$\left(U_{G 1}, U_{A 1}, U_{B 2}\right)$ & $R_{2}^{K}-R_{1}^{L}-S$ & $\pi_{1}+R_{1}^{L}+R_{1}^{I}-R_{1}^{c}-R_{1}^{T}$ & $\pi_{2}+R_{1}^{T}-R_{2}^{K}-C_{0}$ \\
$\left(U_{G 1}, U_{A 2}, U_{B 2}\right)$ & $R_{1}^{K}+R_{2}^{K}-S$ & $\pi_{1}-R_{1}^{K}$ & $\pi_{2}-R_{2}^{K}-C_{0}$ \\
$\left(U_{G 2}, U_{A 1}, U_{B 1}\right)$ & $\pi_{3}$ & $\pi_{1}+R_{1}^{U}+R_{1}^{\omega}+R_{1}^{I}-R_{1}^{c}$ & $\pi_{2}+R_{2}^{U}+R_{2}^{\omega}-R_{2}^{c}+R_{2}^{I}-C_{0}$ \\
$\left(U_{G 2}, U_{A 2}, U_{B 1}\right)$ & $-S$ & $\pi_{1}+R_{2}^{T}$ & $\pi_{2}+R_{2}^{I}-R_{2}^{c}-R_{2}^{T}-C_{0}$ \\
$\left(U_{G 2}, U_{A 1}, U_{B 2}\right)$ & $-S$ & $\pi_{1}+R_{1}^{I}-R_{1}^{c}-R_{1}^{T}$ & $\pi_{2}+R_{1}^{T}-C_{0}$ \\
$\left(U_{G 2}, U_{A 2}, U_{B 2}\right)$ & $-S$ & $\pi_{1}$ & $\pi_{2}-C_{0}$ \\
\hline
\end{tabular}

The expected benefits of green innovation for the government from the unsupervised CMP are as follows:

$$
U_{G 2}=y z\left(\pi_{3}\right)+y(1-z)(-S)+(1-y) z(-S)+(1-y)(1-z)(-S)=y z \pi_{3}+y z S-S
$$

Therefore, the average expected return of the mixed strategy is as follows:

$$
\overline{U_{G}}=x U_{G 1}+(1-x) U_{G 2} .
$$


The replication dynamic equation of the government is as follows:

$$
\begin{aligned}
F(x) & =\frac{\mathrm{d} x}{\mathrm{~d} t}=x\left(U_{G 1}-\overline{U_{G}}\right)=x(1-x)\left(U_{G 1}-U_{G 2}\right) \\
& =x(1-x)\left[y z\left(\pi_{0}-\pi_{3}\right)-y\left(\lambda \theta a_{1}+\mu_{1} Z\right)-z\left(\lambda \theta a_{2}+\mu_{2} Z\right)+\left(\mu_{1} Z+\mu_{2} Z\right)\right] .
\end{aligned}
$$

4.2.2. Replication Dynamic Equation of Cloud of cloud manufacturing enterprise A choosing the "sharing," Manufacturing Enterprise A. Similarly, the expected benefits " nonsharing," and mixed strategies are as follows:

$$
\begin{aligned}
U_{A 1}= & x z\left(\pi_{1}+R_{1}^{L}+R_{1}^{U}+R_{1}^{\omega}+R_{1}^{I}-R_{1}^{c}\right)+x(1-z)\left(\pi_{1}+R_{1}^{L}+R_{1}^{I}-R_{1}^{c}-R_{1}^{T}\right) \\
& +(1-x) z\left(\pi_{1}+R_{1}^{U}+R_{1}^{\omega}+R_{1}^{I}-R_{1}^{c}\right)+(1-x)(1-z)\left(\pi_{1}+R_{1}^{I}-R_{1}^{c}-R_{1}^{T}\right), \\
U_{A 2}= & x z\left(\pi_{1}-R_{1}^{K}+R_{2}^{T}\right)+x(1-z)\left(\pi_{1}-R_{1}^{K}\right)+(1-x) z\left(\pi_{1}+R_{2}^{T}\right)+(1-x)(1-z) \pi_{1}, \\
\overline{U_{A}}= & y\left(U_{A 1}\right)+(1-y) U_{A 2} .
\end{aligned}
$$

The replication dynamic equation of cloud manufacturing enterprise $\mathrm{A}$ is as follows:

$$
\begin{aligned}
F(y) & =\frac{\mathrm{d} y}{\mathrm{~d} t}=y\left(U_{A 1}-\overline{U_{A}}\right)=y(1-y)\left(U_{A 1}-U_{A 2}\right) \\
& =y(1-y)\left(x\left(\lambda \theta a_{1}+\mu_{1} Z\right)+z\left(\left(A_{1}-\left(\theta a_{1}\right)^{-r_{1}}\right)+\omega_{1} \pi_{1}+T \theta a_{1}-T \theta a_{2}\right)+\left((I-C-T) \theta a_{1}\right)\right) .
\end{aligned}
$$

4.2.3. Replication Dynamic Equation of Cloud Manufacturing Enterprise B. Similarly, the expected benefits

of cloud manufacturing enterprise A choosing the "sharing," "nonsharing," and mixed strategies are as follows:

$$
\begin{aligned}
U_{B 1}= & x y\left(\pi_{2}+R_{2}^{L}+R_{2}^{U}+R_{2}^{\omega}+R_{2}^{I}-R_{2}^{c}-C_{0}\right)+x(1-y)\left(\pi_{2}+R_{2}^{L}+R_{2}^{I}-R_{2}^{c}-R_{2}^{T}-C_{0}\right) \\
& +(1-x) y\left(\pi_{2}+R_{2}^{U}+R_{2}^{\omega}-R_{2}^{c}+R_{2}^{I}-C_{0}\right)+(1-x)(1-y)\left(\pi_{2}+R_{2}^{I}-R_{2}^{c}-R_{2}^{T}-C_{0}\right), \\
U_{B 2}= & x y\left(\pi_{2}+R_{1}^{T}-R_{2}^{K}-C_{0}\right)+x(1-y)\left(\pi_{2}-R_{2}^{K}-C_{0}\right)+(1-x) y\left(\pi_{2}+R_{1}^{T}-C_{0}\right)+(1-x)(1-y)\left(\pi_{2}-C_{0}\right), \\
\overline{U_{B}}= & z\left(U_{B 1}\right)+(1-z) U_{B 2} .
\end{aligned}
$$

The replication dynamic equation of cloud manufacturing enterprise $\mathrm{B}$ is as follows:

$$
\begin{aligned}
F(z) & =\frac{\mathrm{d} z}{\mathrm{~d} t}=z\left(U_{B 1}-\overline{U_{B}}\right)=z(1-z)\left(U_{B 1}-U_{B 2}\right) \\
& \left.=z(1-z)\left[x\left(\lambda \theta a_{2}+\mu_{2} K\right)+y\left(\left(A_{2}-\left(\theta a_{2}\right)^{-r_{2}}\right)+\omega_{2} \pi_{2}+T \theta a_{2}-T \theta a_{1}\right)+(I-C-T) \theta a_{2}\right)\right] .
\end{aligned}
$$

4.3. Evolution Path and Stability Analysis of the Tripartite Game. According to evolutionary game theory and the stability theorem of differential equations, if a strategy adopted by the government, cloud manufacturing enterprise 
A, and cloud manufacturing enterprise B is in a stable state, the replication of dynamic equations (11), (13), and (15) needs to satisfy the following conditions:

$$
\begin{gathered}
F(x)=0, \\
\frac{\partial F(x)}{\partial x}<0, \\
F(y)=0, \\
\frac{\partial F(y)}{\partial y}<0, \\
F(z)=0, \\
\frac{\partial F(z)}{\partial z}<0 .
\end{gathered}
$$

Among them,

$$
\begin{aligned}
& \frac{\partial F(x)}{\partial x}=(1-2 x)\left[y z\left(\pi_{0}-\pi_{3}\right)-y\left(\lambda \theta a_{1}+\mu_{1} K\right)-z\left(\lambda \theta a_{2}+\mu_{2} K\right)+\left(\mu_{1} K+\mu_{2} K\right)\right] \\
& \left.\frac{\partial F(y)}{\partial y}=(1-2 y)\left[x\left(\lambda \theta a_{1}+\mu_{1} K\right)+z\left(\left(A_{1}-\left(\theta a_{1}\right)^{-r_{1}}\right)+\omega_{1} \pi_{1}+T \theta a_{1}-T \theta a_{2}\right)+(I-C-T) \theta a_{1}\right)\right] \\
& \left.\frac{\partial F(z)}{\partial z}=(1-2 z)\left[x\left(\lambda \theta a_{2}+\mu_{2} K\right)+y\left(\left(A_{2}-\left(\theta a_{2}\right)^{-r_{2}}\right)+\omega_{2} \pi_{2}+T \theta a_{2}-T \theta a_{1}\right)+(I-C-T) \theta a_{2}\right)\right] .
\end{aligned}
$$

To obtain the system equilibrium point, based on formulas (11), (13), and (15), we can obtain the following eight special equilibrium points of the government and cloud manufacturing enterprises: $\quad E_{1}(0,0,0), E_{2}(0,0,1)$, $E_{3}(0,1,0), E_{4}(0,1,1), E_{5}(1,0,0), E_{6}$
$(1,0,1), E_{7}(1,1,0)$, and $E_{8}(1,1,1)$. According to Lyapunov stability theory, the asymptotic stability of the system can be determined by establishing the Jacobi matrix of the equation and analysing the eigenvalues of the matrix at each equilibrium point as follows:

$$
\left[\begin{array}{ccc}
(1-2 x)\left[y z\left(\pi_{0}-\pi_{3}\right)-y m-z n+(l)\right] & x(1-x)[z S-m] & x(1-x)[y S+n] \\
y(1-y) m & (1-2 y)(x m+z q+i) & y(1-y) q \\
z(1-z) n & z(1-z) j & (1-2 z)[x n+y j+k]
\end{array}\right]
$$

where $\quad m=\lambda \theta a_{1}+\mu_{1} K, n=\lambda \theta \quad a_{2}+\mu_{2} K, i=\quad(I-C-$ $T) \theta a_{1}, k=(I-C-T) \theta \quad a_{2}, l=\mu_{1} K+\mu_{2} K, l=\mu_{1} K+\mu_{2} K$, $q=\left(\begin{array}{ll}A_{1}-\left(\begin{array}{ll}\theta & a_{1}\end{array}\right)^{-r_{1}}\end{array}\right)+\omega_{1} \pi_{1}+T \theta a_{1}-T \theta a_{2}, j=\omega_{2} \pi_{2}+$ $\left(A_{2}-\left(\theta a_{2}\right)^{-r_{2}}\right)+T \theta a_{2}-T \theta a_{1}$

First, the case of the equilibrium point is analysed:

$$
J=\left[\begin{array}{lll}
l & 0 & 0 \\
0 & i & 0 \\
0 & 0 & k
\end{array}\right]
$$

The eigenvalues of the Jacobi matrix are $\lambda_{1}=l, \lambda_{2}=i$, and $\lambda_{3}=k$. By analogy, by substituting the eight equilibrium points into the Jacobi matrix (19), the eigenvalues of the Jacobi matrix corresponding to the equilibrium points can be obtained, as shown in Table 4 .
To analyse the symbols of the eigenvalues corresponding to different equilibrium points without losing generality, we assume that when $n+l>0, \pi_{0}-\pi_{3}-m-n+l>0$, $l-m>0$, and $(I-C-T)>0$, the net income of the government when it chooses to supervise is greater than that when it chooses not to supervise, and its net income is positive. Cloud manufacturing enterprises $\mathrm{A}$ and $\mathrm{B}$ conduct shared cloud manufacturing innovation, i.e., the sum of the information revenue is greater than the channel cost and technological loss. We discuss the stability strategy of the evolutionary game in three cases, and the results are listed in Table 5.

Case 1. When $j+k>0,(n+j+k)>0$. Thus, regardless of whether the government chooses the supervision strategy, 
TABLE 4: Eigenvalues of Jacobi matrix at each equilibrium point.

\begin{tabular}{lccc}
\hline Equilibrium point & \multicolumn{2}{c}{ Characteristic value } \\
& $\lambda_{1}$ & $\lambda_{2}$ & $\lambda_{3}$ \\
\hline$E_{1}(0,0,0)$ & $l$ & $i$ & $k$ \\
$E_{2}(0,0,1)$ & $n+l$ & $q+i$ & $-k$ \\
$E_{3}(0,1,0)$ & $l-m$ & $-i$ & $j+k$ \\
$E_{4}(0,1,1)$ & $\pi_{0}-\pi_{3}-m-n+l$ & $-(q+i)$ & $n+k$ \\
$E_{5}(1,0,0)$ & $-l$ & $m+i$ & $-(n+k)$ \\
$E_{6}(1,0,1)$ & $-(n+l)$ & $m+q+i$ & $(n+j+k)$ \\
$E_{7}(1,1,0)$ & $-(l-m)$ & $-(m+i)$ & $-(n+j+k)$ \\
$E_{8}(1,1,1)$ & $-\left(\pi_{0}-\pi_{3}-m-n+l\right)$ & $-(m+q+i)$ & \\
\hline
\end{tabular}

TABle 5: Local stability of equilibrium (Cases 1, 2, and 3).

\begin{tabular}{lcccccccccccc}
\hline & \multicolumn{4}{c}{ Characteristic value } & \multicolumn{3}{c}{ Characteristic value } & \multicolumn{3}{c}{ Characteristic value } \\
Equilibrium point & $\lambda_{1}$ & $\lambda_{2}$ & $\lambda_{3}$ & Stability & $\lambda_{1}$ & $\lambda_{2}$ & $\lambda_{3}$ & Stability & $\lambda_{1}$ & $\lambda_{2}$ & $\lambda_{3}$ & Stability \\
\hline$E_{1}(0,0,0)$ & + & + & + & Saddle point & + & + & + & Saddle point & + & + & + & Saddle point \\
$E_{2}(0,0,1)$ & + & + & - & Unstable point & + & + & - & Unstable point & + & + & - & Unstable point \\
$E_{3}(0,1,0)$ & + & - & + & Unstable point & + & - & - & Unstable point & + & - & - & Unstable point \\
$E_{4}(0,1,1)$ & + & - & - & Unstable point & + & - & + & Unstable point & + & - & + & Unstable point \\
$E_{5}(1,0,0)$ & - & + & + & Unstable point & - & + & + & Unstable point & - & + & + & Unstable point \\
$E_{6}(1,0,1)$ & - & + & - & Unstable point & - & + & - & Unstable point & - & + & - & Unstable point \\
$E_{7}(1,1,0)$ & - & - & + & Unstable point & - & - & + & Unstable point & - & - & - & ESS \\
$E_{8}(1,1,1)$ & - & - & - & ESS & - & - & - & ESS & - & - & + & Unstable point \\
\hline
\end{tabular}

the revenue obtained by cloud manufacturing enterprise B from choosing shared innovation is greater than that obtained by performing green innovation activities alone. Moreover, Table 4 shows that none of the eigenvalues of the Jacobi matrix corresponding to equilibrium point E8 are positive. In this case, the system is stable at point $E_{8}(1,1,1)$.

Case 2. When $j+k>0,(n+j+k)>0$. Thus, when the government chooses the nonsupervision strategy, the revenue obtained by cloud manufacturing enterprise B from sharing in innovation is less than that obtained from its green innovation activities alone. In contrast, the results are the opposite. Moreover, Table 4 shows that none of the eigenvalues of the Jacobian matrix corresponding to equilibrium point $E_{8}$ is positive. In this case, the system is stable at point $E_{8}(1,1,1)$.

Case 3. When $j+k>0,(n+j+k)<0$; thus, regardless of whether the government chooses the supervision strategy, the revenue obtained by cloud manufacturing enterprise $\mathrm{B}$ from choosing shared innovation is less than that obtained by the enterprise carrying out green innovation activities alone. In this case, as shown in Table 4, none of the eigenvalues of the Jacobian matrix corresponding to equilibrium point $E_{7}$ is positive. In this case, the system is stable at point $E_{7}(1,1,0)$.

\section{Numerical Experiment and Simulation}

In this paper, MATLAB software is used to simulate the dynamic evolutionary process of the strategy selection of the government, enterprise $\mathrm{A}$, and enterprise $\mathrm{B}$ under different initial states. The following are the assumptions of the initial values of the payment matrix parameters: $S=10, \lambda=0.3$, $\theta=0.2, a_{1}=8, a_{2}=3, A_{1}=0.5, A_{2}=0.3, \mu_{1}=0.5, \mu_{2}=0.2$, $r_{1}=0.3, r_{2}=0.4, \omega_{1}=0.3, \omega_{2}=0.1, \pi_{0}=5, \pi_{1}=5, \pi_{2}=2$, $\pi_{3}=2, C=0.3, I=0.7, T=0.2$, and $K=8$. Based on the simulation analysis results, the initial participation intention of the participants, the incentive policies of the government, the punishment intensity, the informatization degree, and the saturation of the cloud platform are discussed.

5.1. Influence of a Change in the Initial Value on the System Evolution Results. Considering the singleness of the initial value setting of the three-party game subject strategy in the scenario analysis above, this paper tests the evolution results of the group strategy by adjusting the initial value to eliminate the influence of initial value selection on the credibility of the results and enhance their persuasiveness.

Figure 1 shows the simulation of the impact of the initial willingness of the government and cloud manufacturing enterprises $\mathrm{A}$ and $\mathrm{B}$ to participate in sharing innovation for green innovation. Suppose that the government, enterprise $A$, and enterprise $B$ have the same initial intention, which is $x=y=z$, where $x, y$, and $z$ assume the values of $0.3,0.5$, and 0.7 , respectively. The figure shows that the larger the proportion of the regulatory strategy chosen by the government, the faster the system evolves to 1 . Based on the premise of meeting the interests of all parties, the difference in the initial value setting of $x, y$, and $z$ will have a certain influence on the evolutionary path of the system strategy but will not change the final strategy choice of the three parties. 


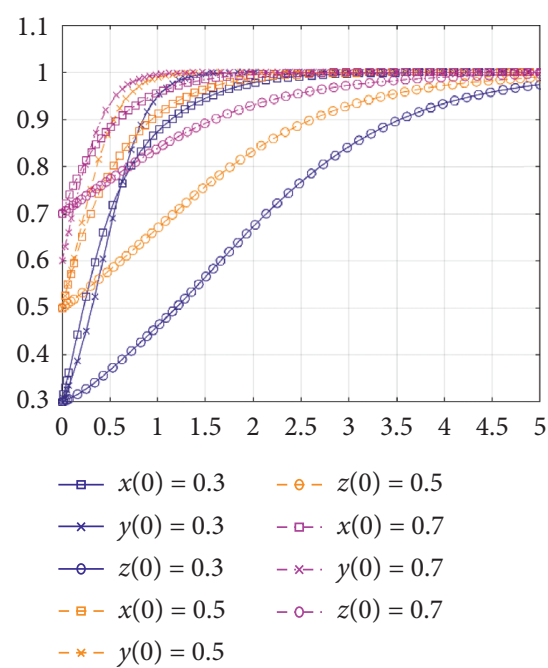

(a)

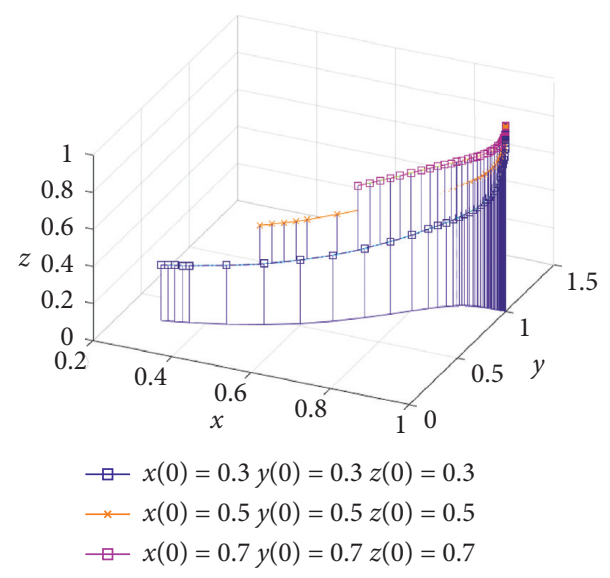

(b)

FIGURE 1: Evolution trends for the initial willingness of the government $x=0.3,0.5$, and 0.7 , the initial willingness of enterprise A $y=0.3,0.5$, and 0.7 , and the initial willingness of enterprise $\mathrm{B} z=0.3,0.5$, and 0.7 .

Figure 2 shows the simulation of the impact of a change in the government's initial regulatory intention on cloud manufacturing enterprises A and B participating in collaborative innovation with the other parameters unchanged. Once the initial sharing intention of the government changes from 0.3 to 0.7 , the initial willingness $y$ and $z$ of enterprises A and B converge to 1 . Meanwhile, as $x$ increases, the convergence speed of $y$ and $z$ is accelerated, and $y$ converges faster. Finally, the final equilibrium point of the system evolution result of the change in the government participation willingness $x$ converges to $(1,1,1)$. The simulation results show that as the government's initial supervision willingness $x$ increases, the participation willingness of enterprises A and B gradually strengthens, and the participation intention of enterprise $B$ is greatly affected by the government.

Figure 3 shows the simulation of the impact of a change in cloud manufacturing enterprise A's initial regulatory intention on the government and cloud manufacturing enterprise $\mathrm{B}$ participating in a collaborative innovation strategy with the other parameters unchanged. Once the initial sharing intention of enterprise A changes from 0.3 to 0.7 , the initial willingness $x$ and $z$ of the government and enterprise B converge to 1 . Meanwhile, as $y$ increases, the convergence speed of $x$ and $z$ is accelerated, and $x$ converges faster. Finally, the change in the government participation willingness $x$ converges to $(1,1,1)$. The simulation results show that if the government's and enterprise B's willingness to participate remains unchanged, even if firm A's initial willingness to share increases, the government is more sensitive to a change in the initial sharing willingness $y$ of enterprise A.

Figure 4 shows the simulation of the impact of a change in cloud manufacturing enterprise B's initial regulatory intention on the government and cloud manufacturing enterprise A participating in a collaborative innovation strategy with the other parameters unchanged. Once the initial sharing intention $\mathrm{z}$ of enterprise $\mathrm{B}$ changes from 0.3 to 0.7 , the willingness $x$ and $y$ converges to 1 . The convergence speed of $y$ is greater than that of $x$, and the equilibrium point of the system evolution converges to $(1,1,1)$. The simulation results show that if the government and firm A's willingness to participate remains unchanged, even if firm B's initial willingness to share increases, enterprise A is more sensitive to a change in the initial sharing willingness $z$.

5.2. Influence of Government Incentive $\lambda$ on the System Evolution Results. Figure 5 shows the simulation of the impact of the government's incentive to conduct green technology innovation on the cloud manufacturing enterprises' participation in collaborative innovation with the other parameters unchanged. As shown in Figure 5(a), as the government incentive $\lambda$ increases from 0.2 to 0.6 , the convergence rates of $y$ and $z$ accelerate and gradually converge to 1 , and the change in the convergence speed of enterprise B is greater than that of enterprise A. Figure 5(b) also shows that the final equilibrium point of the system tends towards $(1,1,1)$, i.e., the final strategy of the tripartite game players is (supervision, sharing and sharing). The simulation results show that an increase in government incentives can enhance the willingness of the enterprises to share and that the incentive coefficient has a greater impact on the strategy choice of enterprise $\mathrm{B}$. This is because enterprise $B$ needs to pay part of access cost $C_{0}$ due to its backward technology when entering the platform, and the government's incentive can reduce the cost of cloud platform technology innovation, which, in turn, affects enterprise B's participation in cloud platform technology innovation. When the government incentive is large, the willingness of the enterprises to participate will naturally increase, and the enterprises will ultimately choose to participate in shared innovation. 


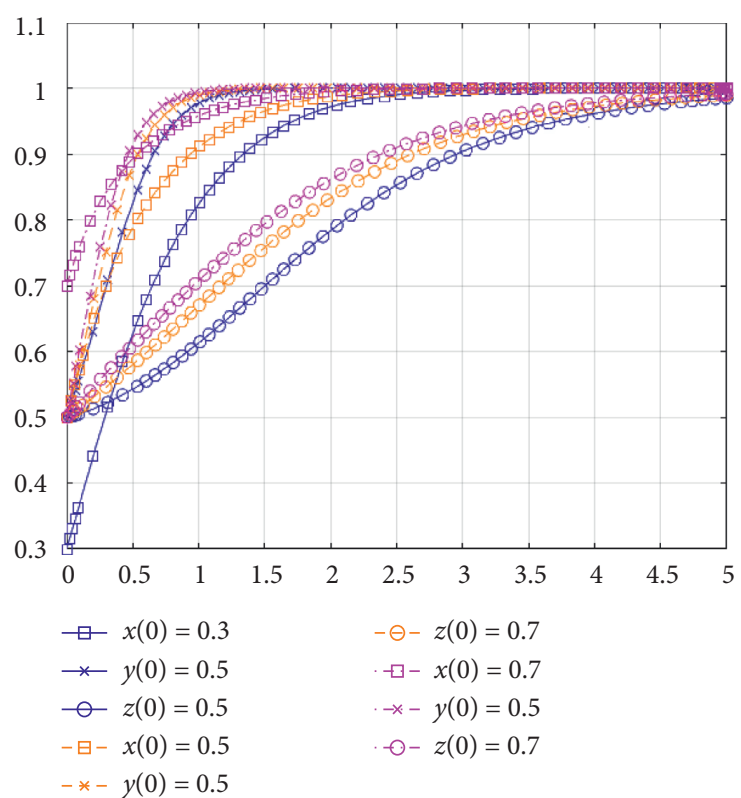

(a)

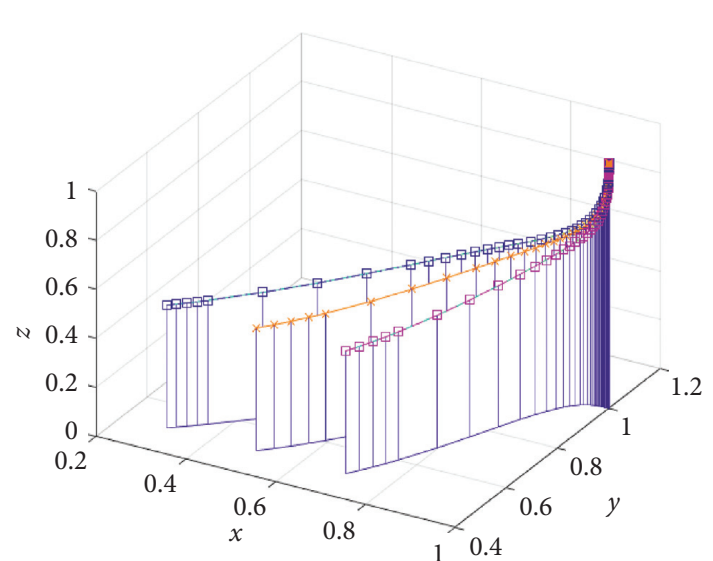

$\square-x(0)=0.3 y(0)=0.5 z(0)=0.5$

$\leadsto x(0)=0.5 y(0)=0.5 z(0)=0.5$

$-\boxminus-x(0)=0.7 y(0)=0.5 z(0)=0.5$

(b)

FIGURE 2: Evolution trends for the initial willingness of the government $x=0.3,0.5$, and 0.7 , the initial willingness of enterprise A $y=0.5$, and the initial willingness of enterprise $\mathrm{B} z=0.5$.

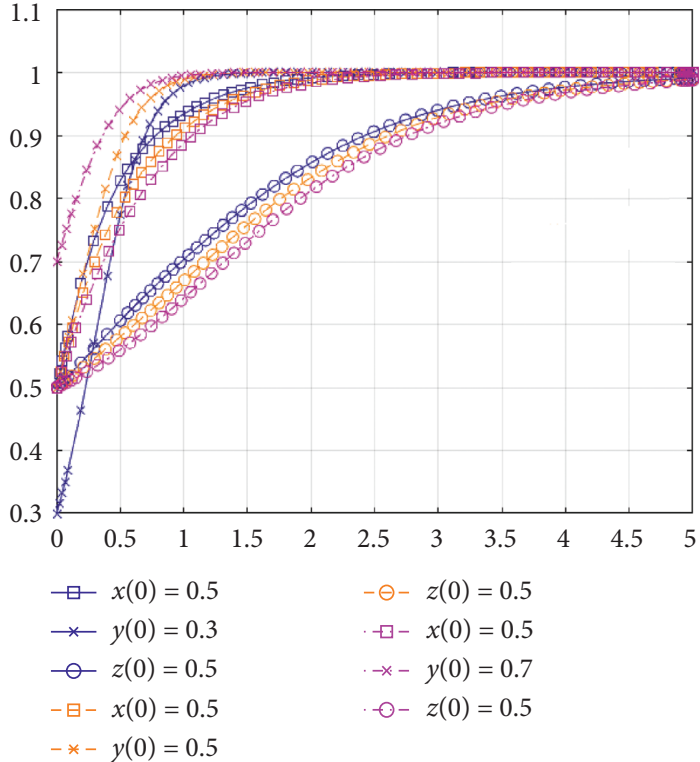

(a)

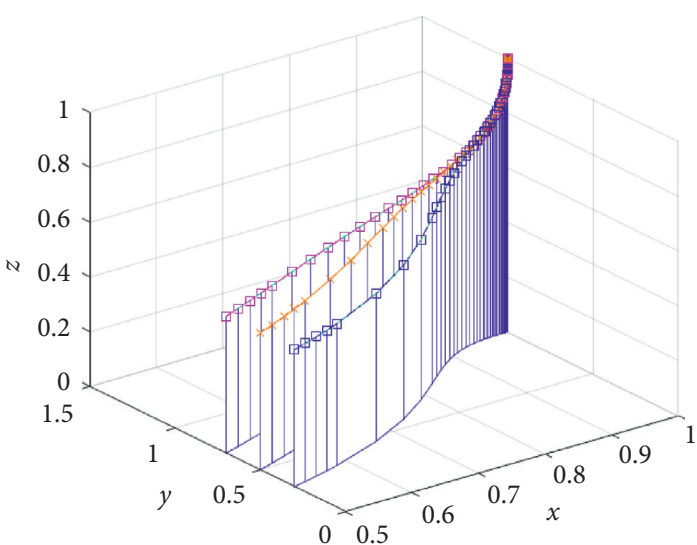

$-\exists-x(0)=0.5 y(0)=0.3 z(0)=0.5$

$\multimap x(0)=0.5 y(0)=0.5 z(0)=0.5$

一曰- $x(0)=0.5 y(0)=0.7 z(0)=0.5$

(b)

Figure 3: Evolution trends for the initial willingness of enterprise A $y=0.3,0.5$, and 0.7 , and the initial willingness of the government $x=0.5$, and the initial willingness of enterprise $\mathrm{B} z=0.5$.

5.3. Impact of Cloud Platform Informatization on the System Evolution Results. Figure 6 shows the simulation of the impact of the government's default penalty coefficient $K$ on the cloud manufacturing enterprises' participation in green technology innovation with the other parameters unchanged. Figure 6 shows that as the penalty coefficient $K$ increases from 2 to 10 , the convergence speed of $K$ is accelerated and gradually converges to 1 , and the critical value of default penalty $K$ is between 2 and 4 . When $K$ is less than the critical value, $z$ converges to 0 , and the system converges to the stable point $(1,1,0)$. In contrast, the stable equilibrium point of the system tends to $(1,1,1)$. Moreover, the convergence rate of $y$ and $z$ increases as $K$ increases, and the convergence speed of enterprise $B$ is greater than that of enterprise A. The simulation results shown in Figure 6 suggest that an increase in the default penalty can 


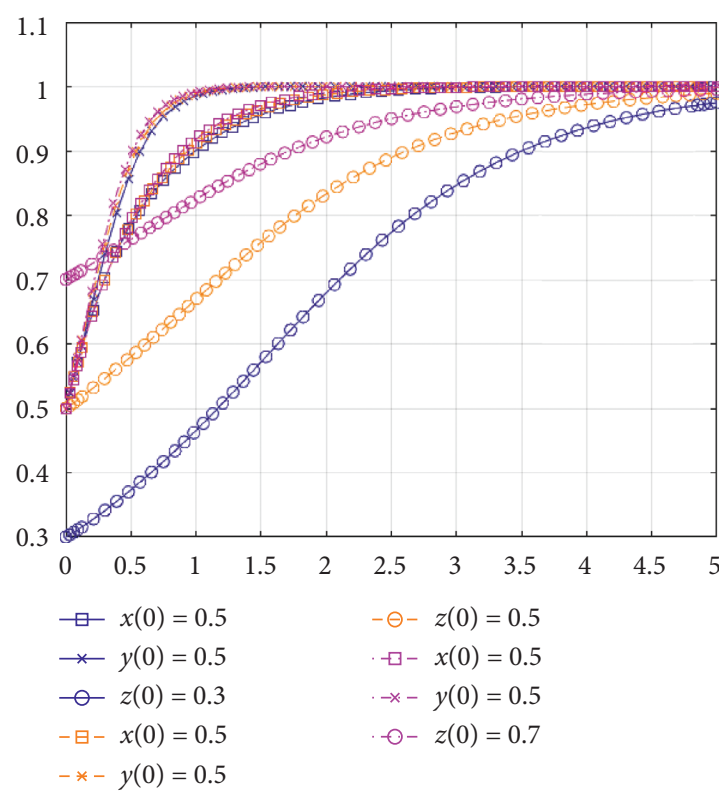

(a)

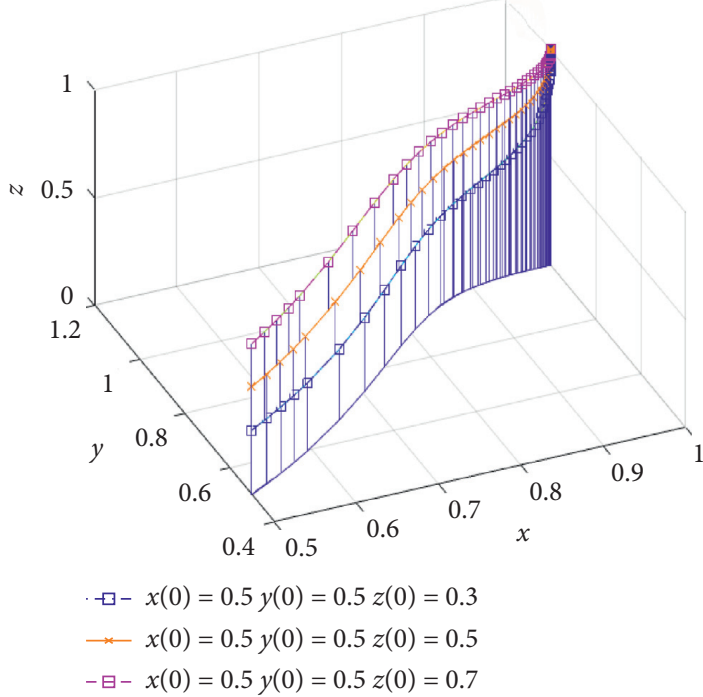

(b)

FIGURE 4: Evolution trends for the initial willingness of enterprise $\mathrm{B} z=0.3,0.5$, and 0.7 , the initial willingness of the government $x=0.5$, and the initial willingness of enterprise A $y=0.5$.

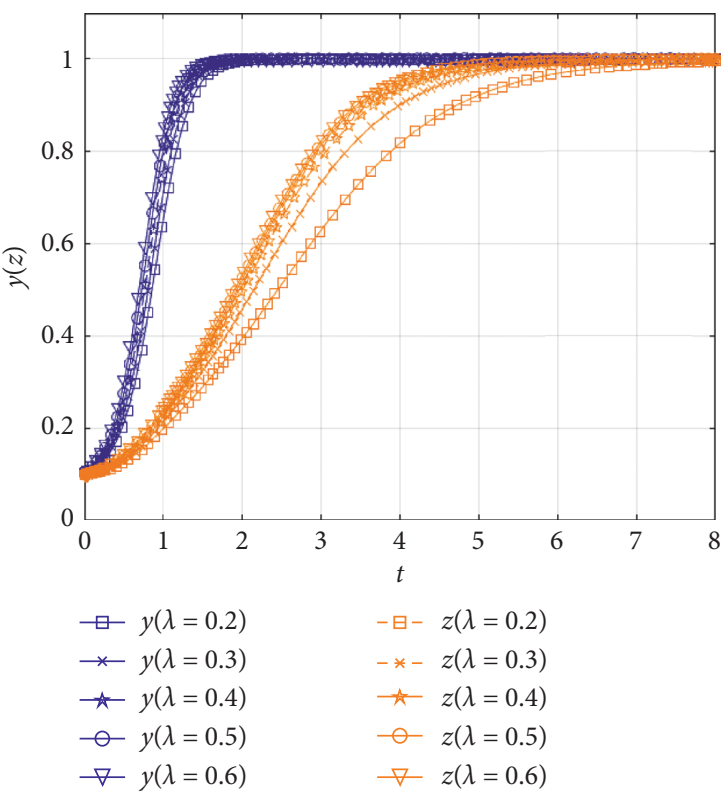

(a)

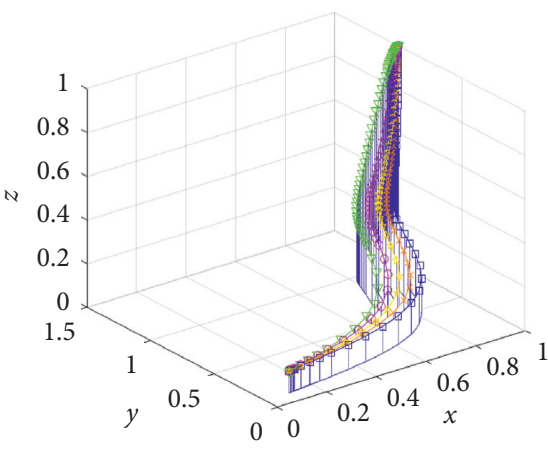

$$
\begin{aligned}
& \square(\lambda=0.2) \quad \bigcirc(\lambda=0.5) \\
& \text { - } *-(\lambda=0.3) \quad \nabla-(\lambda=0.6) \\
& \therefore(\lambda=0.4)
\end{aligned}
$$

(b)

Figure 5: Evolution trends for the government incentives $\lambda=0.2,0.3,0.4,0.5$, and 0.6 and the initial willingness $x=y=z=0.1$. While $\lambda$ increases, the cooperation willingness of $x, y$, and $z$ increases to 1 .

enhance the enterprises' willingness to share and that the punishment intensity has a greater impact on the strategy selection of enterprise B. This is because the goal of the enterprises is to pursue their own interests. Once the enterprises perceive that participation is unfavourable to them, their willingness to participate will immediately change. When the punishment is small, it is difficult for enterprise B to cooperate with enterprise A, leading to the possibility of noncollaborative innovation. In contrast, when the punishment imposed on enterprise $A$ is large, even if enterprise A does not participate in collaborative innovation, enterprise $\mathrm{B}$ will also obtain some revenues. Moreover, the willingness of enterprise A to participate will increase, resulting in the willingness of enterprise $\mathrm{B}$ to participate. 


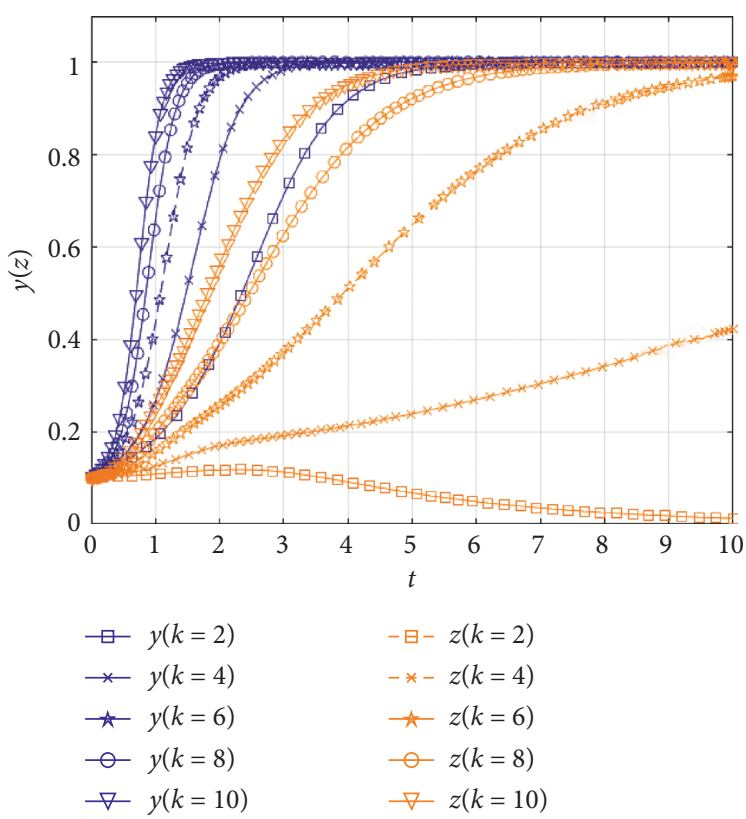

(a)

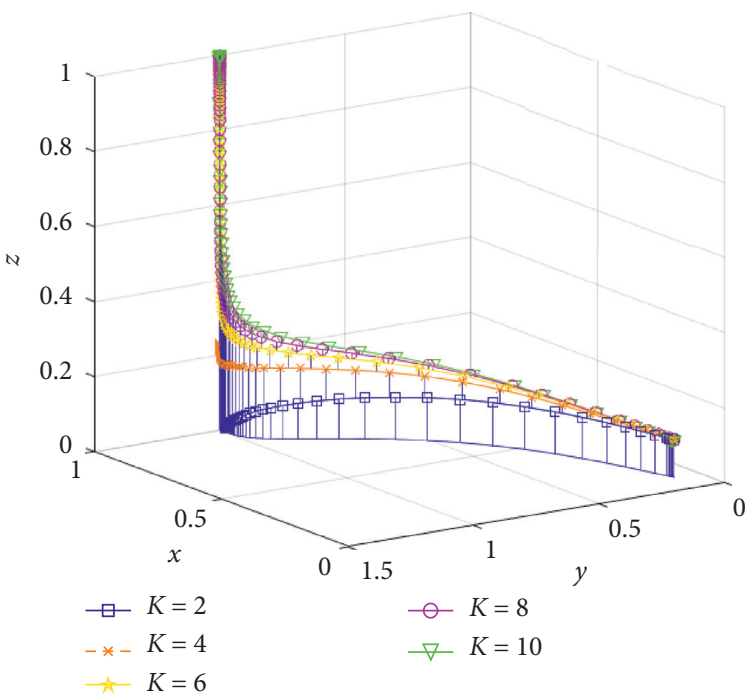

(b)

Figure 6: Evolution trends for the penalty coefficient $K=2,4,6,8$, and 10 and the initial willingness $x=y=z=0.1$. A common tendency is that the cooperation willingness of $x, y$, and $z$ increases to 1 with the increase of penalty coefficient $K$, except for $K=2$.

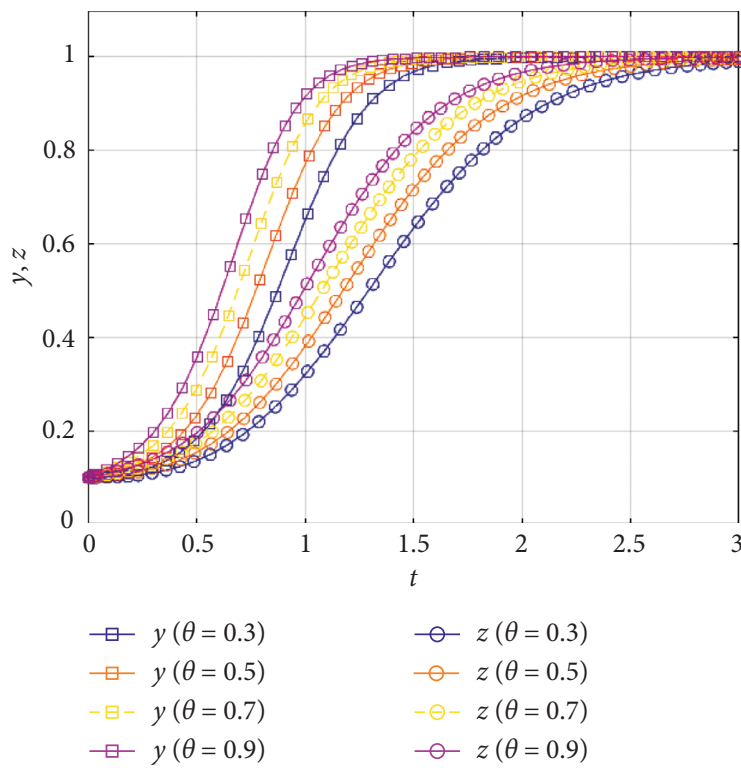

(a)

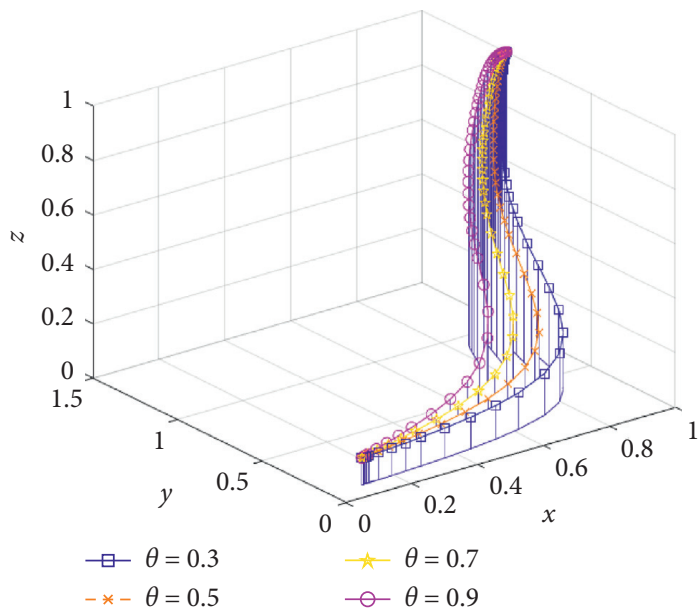

(b)

FIGURE 7: Evolution trends for cloud platform informatization degree $\theta=2,4,6,8$, and 10 and the initial willingness $x=y=z=0.1$. With the increase of $\theta$, the willingness of cooperation of $x, y$, and $z$ increases.

5.4. Impact of Cloud Platform Informatization $\theta$ on the System Evolution Results. Figure 7 shows the simulation of the impact of a change in the cloud platform informatization degree $\theta$ on the cloud manufacturing enterprises' participation in green technology innovation with the other parameters unchanged. As the cloud platform informatization degree $\theta$ increases from 0.3 to 0.9 , the convergence speed of $y$ and $z$ accelerates and gradually converges to 1 . Figure 7(b) shows that the final equilibrium point of the system tends towards $(1,1,1)$, and the final strategy of the tripartite game players is (supervision and sharing and sharing). The simulation results show that an increase in cloud platform informatization can enhance the enterprises' willingness to share because the goal of the enterprises is to pursue their 


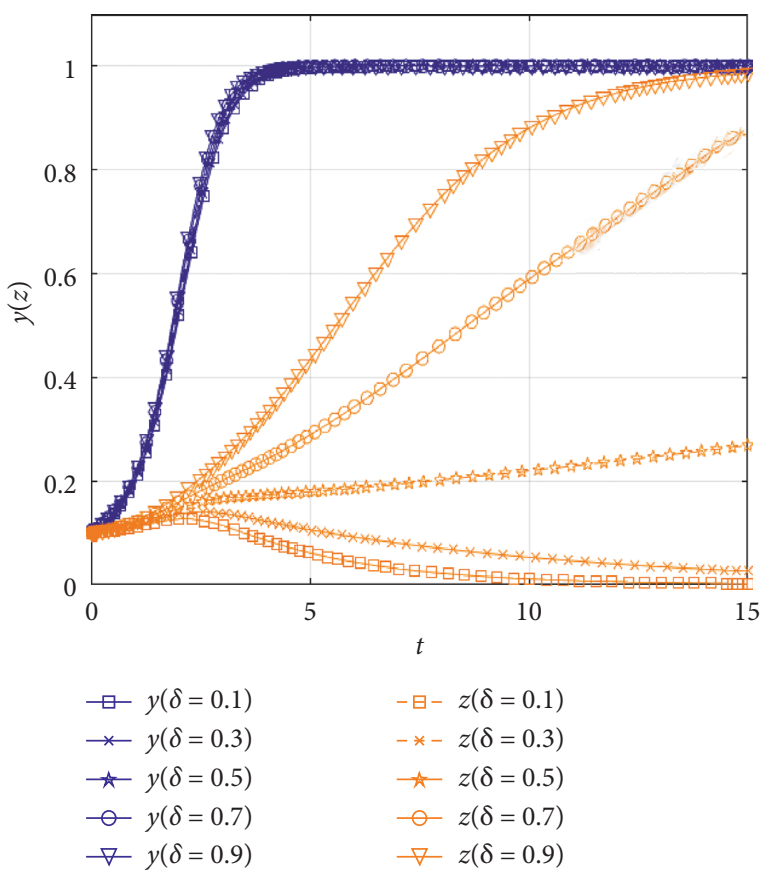

(a)

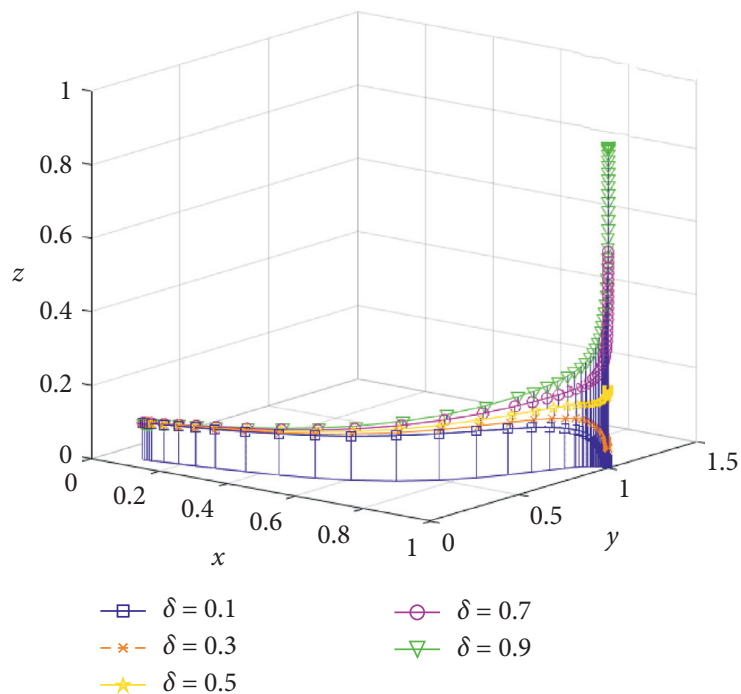

(b)

FIGURE 8: Evolution trends for cloud platform saturation $\delta=2,4,6,8$, and 10 and the initial willingness $x=y=z=0.1$. In the figure, if the saturation of the cloud platform is low, that is, $x<0.5$, the system will converge to $(1,1,0)$. Conversely, if $x>0.5$, the system will converge to $(1,1,1)$.

own interests. When the information level of the cloud platform is high, one enterprise's willingness to participate will slowly increase until the other enterprise's willingness to participate increases to a certain value. The enterprises' willingness to participate will rapidly increase, and the enterprises will ultimately choose shared innovation.

5.5. Impact of Cloud Platform Saturation on the System Evolution Results. Figure 8 shows a simulation of the impact of changes in cloud platform saturation $A_{1}$ and $A_{2}$ on the cloud manufacturing enterprises' participation in green technology innovation (assuming $A_{1}=A_{2}=\delta$ ) with the other parameters unchanged. As shown in Figure 8 , as the cloud platform saturation increases from 0.1 to 0.9 , the convergence speed increases and gradually converges to 1 , and the critical value of $\delta$ is between 0.5 and 0.7 . When the convergence speed is less than the critical value, $z$ converges to 0 , and the stable equilibrium point of the system tends to $(1,1,0)$. In contrast, $y$ and $z$ converge to 1 , and the system converges to the stable point $(1,1,1)$. Moreover, an increase in $\delta$ accelerates the convergence speed of $y$ and $z$, while the convergence speed of enterprise $\mathrm{A}$ is faster than that of enterprise B. The simulation results shown in Figure 8 suggest that an increase in cloud platform saturation can enhance enterprises' willingness to share and that the saturation of the cloud platform has a greater impact on the strategy selection of enterprise $B$. This is because that the goal of the enterprise is to seek cooperation and pursue benefits. When the saturation of the cloud platform is low, it is difficult for the enterprises to cooperate with other enterprises; thus, there is a greater possibility of noncollaborative innovation. Furthermore, the enterprises' willingness to participate in collaborative innovation will decline, and the enterprises will ultimately choose noncollaborative innovation. When platform saturation increases, enterprises will naturally make more choices of cooperation and ultimately participate in collaborative innovation.

\section{Conclusion}

Based on the bounded rationality of the game players, this paper establishes a payment matrix for a green collaborative innovation game involving the government and cloud manufacturing enterprises $\mathrm{A}$ and $\mathrm{B}$ and systematically analyses the decision-making evolutionary process of green collaborative innovation. Then, combined with a numerical analysis, the collaborative innovation strategy behaviour and influencing factors of the government and cloud manufacturing enterprises $\mathrm{A}$ and $\mathrm{B}$ are investigated.

(1) The government and cloud manufacturing enterprises $A$ and $B$ have different degrees of influence on each other's willingness to participate. This finding is mainly reflected in the following two aspects: (1) the behaviour of enterprise $\mathrm{A}$ is less affected by the government and enterprise B's willingness to participate and is mainly affected by the market. Enterprise B is greatly affected by the government's willingness to participate. For example, in the current green collaborative innovation 
cloud platform, enterprise B's amount of participation is much higher than that of enterprise A. (2) The influences of cloud manufacturing enterprises A and B on each other are asymmetric, and enterprise $B$ is more sensitive to changes in enterprise A's willingness to participate in collaboration. As enterprise A's participation increases, green innovation technology and innovation resources accumulate, and the number of enterprises A participating further increases. Therefore, the government should give subsidies to enterprise A, enhance the enthusiasm of enterprise A to engage in collaborative innovation, allow enterprise $A$ to take the lead, cooperate extensively with enterprise $B$, and make full use of the existing resources. The government should play a guiding role and jointly create a good cloud platform innovation environment for green collaborative innovation.

(2) Cloud manufacturing enterprise B is more sensitive to government incentives. Policy support, such as achievement transformation, preferential tax treatment, and government procurement, reduces the cost of green collaborative innovation incurred by enterprises and the sales risk of new products, improves the conversion rate of new technologies, attracts more high-tech enterprises to join the collaborative innovation centre, and further attracts enterprise $B$ to participate in the cloud manufacturing collaborative innovation centre. Therefore, the government should formulate different preferential incentive policies, such as preferential tax policies for enterprises.

(3) The greater the degree of cloud platform informatization is, the greater the participation of cloud manufacturing enterprises is. Therefore, it is necessary to strengthen the management of cloud platforms and enhance the informatization degree of such platforms to enhance enterprises' willingness to share and promote the pursuit of profit maximization through cooperation between enterprises.

(4) Cloud manufacturing enterprise B is more sensitive to punishment and cloud platform saturation than enterprise A. Enterprise B pursues green technology innovation and maximization of economic benefits. The greater the degree of punishment is, the more that enterprises are able to restrain their behaviour, which, in turn, promotes innovation behaviour by enterprises. Additionally, the greater the saturation of the cloud platform is, the greater the amount of technologies and resources that enterprises can share is. Therefore, it is necessary for the government to appropriately increase the punishment for errant enterprises, and negative incentives can be used to guide enterprises to conduct cloud manufacturing green collaborative innovation. The government can attract more enterprises to join green innovation activities on cloud platforms, which can enhance enterprises' enthusiasm to engage in collaborative innovation.

\section{Data Availability}

The data used to support the findings of this study are included within the article.

\section{Conflicts of Interest}

The authors declare that they have no conflicts of interest.

\section{Acknowledgments}

The authors thank the Youth Foundation of Philosophy and Social Science Research Planning of Heilongjiang Province (No. 18JYC257); the Young Innovative Talents Training Program of Heilongjiang Province (No. UNPYSCT2018151); the Postdoctoral Fund Project of Heilongjiang Province (No. LBH-Z18015); and the Young Talents Project of Northeast Agricultural University (No. 17QC30); the Key Research Topic of Economic and Social Development of Heilongjiang Province in 2020 (No. 20211).

\section{References}

[1] B.-H. Li, B.-C. Hou, W.-T. Yu, X.-B. Lu, and C.-W. Yang, "Applications of artificial intelligence in intelligent manufacturing: a review," Frontiers of Information Technology \& Electronic Engineering, vol. 18, no. 1, pp. 86-96, 2017.

[2] A. Thierer, C. Koopman, A. Hobson et al., "How the internet, the sharing economy, and reputational feedback mechanisms solve the lemons problem," Social Science Electronic Publishing, vol. 70, p. 830, 2015.

[3] C. C. Menassa, "Evaluating sustainable retrofits in existing buildings under uncertainty," Energy and Buildings, vol. 43, no. 12, pp. 3576-3583, 2011.

[4] V. Issarny, N. Georgantas, S. Hachem et al., "Service-oriented middleware for the future internet: state of the art and research directions," Journal of Internet Services and Applications, vol. 2, no. 1, pp. 23-45, 2011.

[5] P. Shrivastava, "The role of corporations in achieving ecological sustainability," Academy of Management Review, vol. 20, no. 4, pp. 936-960, 1995.

[6] M. D. Plessis, "The strategic drivers and objectives of communities of practice as vehicles for knowledge management in small and medium enterprises," International Journal of Information Management, vol. 28, no. 1, pp. 61-67, 2008.

[7] X. Gao, J. Shen, W. He et al., "An evolutionary game analysis of governments' decision-making behaviors and factors influencing watershed ecological compensation in China," Journal of Environmental Management, vol. 251, Article ID 109592, 2019.

[8] Y. Chen, J. Zhang, P. R. Tadikamalla, and X. Gao, "The relationship among government, enterprise, and public in environmental governance from the perspective of multi-player evolutionary game," International Journal of Environmental Research and Public Health, vol. 16, no. 18, p. 3351, 2019.

[9] O. Fatahi Valilai and M. Houshmand, "A platform for optimisation in distributed manufacturing enterprises based on cloud manufacturing paradigm," International Journal of Computer Integrated Manufacturing, vol. 27, no. 11, pp. 1031-1054, 2014.

[10] B. H. Li, L. Zhang, L. Ren et al., "Further discussion on cloud manufacturing," Computer Integrated Manufacturing Systems, vol. 17, no. 3, pp. 449-457, 2011. 
[11] B. H. Li, L. Zhang, L. Ren et al., "Typical characteristics, technologies and applications of cloud manufacturing," Computer Integrated Manufacturing Systems, vol. 18, no. 7, pp. 1345-1356, 2012.

[12] B. H. Li, L. Zhang, S. L. Wang et al., "Cloud manufacturing: a new service-oriented networked manufacturing model," Computer Integrated Manufacturing Systems, vol. 16, no. 1, pp. 1-7, 2010.

[13] A. Simeone, A. Caggiano, and Y. Zeng, "Smart cloud manufacturing platform for resource efficiency improvement of additive manufacturing services," Procedia CIRP, vol. 88 , pp. 387-392, 2020.

[14] H. S. Kang, J. Y. Lee, S. Choi et al., "Smart manufacturing: past research, present findings, and future directions," International Journal of Precision Engineering and ManufacturingGreen Technology, vol. 3, no. 1, pp. 111-128, 2016.

[15] F. Ameri, C. Urbanovsky, and C. McArthur, "A systematic approach to engineering knowledge organization and modeling," in Proceedings of the International Design Engineering Technical Conferences and Computers and Information in Engineering Conference, pp. 947-958, American Society of Mechanical Engineers, Chicago, IL, USA, August 2012.

[16] A. E. Roth and E. Peranson, "The redesign of the matching market for American physicians: some engineering aspects of economic design," American Economic Review, vol. 89, no. 4, pp. 748-780, 1999.

[17] D. Z. Zhao and R. Li, "Two-sided matching mechanism with agents' expectation for cloud manufacturing resource," Control and Decision, vol. 32, no. 5, pp. 871-878, 2017.

[18] L. F. He and D. Z. Zhao, "Multi layer inventory transportation optimization and fuzzy game coordination in reactive supply chain," Systems Engineering Theory and Practice, vol. 31, no. 6, pp. 1045-1055, 2011.

[19] F. Tao, L. Zhang, H. Guo et al., "Typical characteristics of cloud manufacturing and several key issues of cloud service composition," Computer Integrated Manufacturing Systems, vol. 17, no. 3, pp. 477-486, 2011.

[20] R. Y. Zhong, S. Lan, C. Xu et al., "Visualization of RFIDenabled shopfloor logistics big data in cloud manufacturing," The International Journal of Advanced Manufacturing Technology, vol. 84, no. 1-4, pp. 5-16, 2016.

[21] P. Argoneto and P. Renna, "Supporting capacity sharing in the cloud manufacturing environment based on game theory and fuzzy logic," Enterprise Information Systems, vol. 10, no. 2, pp. 193-210, 2016.

[22] J. Mun, M. Shin, and M. Jung, “A goal-oriented trust model for virtual organization creation," Journal of Intelligent Manufacturing, vol. 22, no. 3, pp. 345-354, 2011.

[23] A. Gharaei, S. A. Hoseini Shekarabi, and M. Karimi, "Modelling and optimal lot-sizing of the replenishments in constrained, multi-product and bi-objective EPQ models with defective products: generalised cross decomposition," International Journal of Systems Science: Operations \& Logistics, vol. 7, no. 3, pp. 262-274, 2020.

[24] A. A. Zaid, A. A. M. Jaaron, and A. Talib Bon, "The impact of green human resource management and green supply chain management practices on sustainable performance: an empirical study," Journal of Cleaner Production, vol. 204, pp. 965-979, 2018.

[25] J. Sarkis, S. Talluri, and A. Gunasekaran, "A strategic model for agile virtual enterprise partner selection," International Journal of Operations \& Production Management, vol. 27, no. 11, pp. 1213-1234, 2007.

[26] S. B. Brunnermeier and M. A. Cohen, "Determinants of environmental innovation in US manufacturing industries,"
Journal of Environmental Economics and Management, vol. 45, no. 2, pp. 278-293, 2003.

[27] J. Doran and G. Ryan, "Regulation and firm perception, ecoinnovation and firm performance," European Journal of Innovation Management, vol. 15, no. 4, pp. 421-441, 2012.

[28] B. Lin and Y. Chen, "Does electricity price matter for innovation in renewable energy technologies in China?" Energy Economics, vol. 78, pp. 259-266, 2019.

[29] E. M. Tachizawa and C. Y. Wong, "The performance of green supply chain management governance mechanisms: a supply network and complexity perspective," Journal of Supply Chain Management, vol. 51, no. 3, pp. 18-32, 2015.

[30] Y. Tian, K. Govindan, and Q. Zhu, "A system dynamics model based on evolutionary game theory for green supply chain management diffusion among Chinese manufacturers," Journal of Cleaner Production, vol. 80, pp. 96-105, 2014.

[31] H. Sun, Y. Wan, L. Zhang, and Z. Zhou, "Evolutionary game of the green investment in a two-echelon supply chain under a government subsidy mechanism," Journal of Cleaner Production, vol. 235, pp. 1315-1326, 2019.

[32] M. E. Porter and C. V. D. Linde, "Green and competitive: ending the stalemate," Harvard Business Review, vol. 28, no. 6, pp. 128-129, 1999.

[33] A. B. Jaffe and K. Palmer, "Environmental regulation and innovation: a panel data study," Review of Economics and Statistics, vol. 79, no. 4, pp. 610-619, 1997.

[34] R. Dwyer, D. Lamond, J. F. Molina-Azorín et al., "Green management and financial performance: a literature review," Management Decision, vol. 47, no. 7, pp. 1080-1100, 2009.

[35] C. Ghisetti and F. Quatraro, "Green technologies and environmental productivity: a cross-sectoral analysis of direct and indirect effects in Italian regions," Ecological Economics, vol. 132, pp. 1-13, 2017.

[36] M. A. Cohen and A. Tubb, "The impact of environmental regulation on firm and country competitiveness: a metaanalysis of the porter hypothesis," Journal of the Association of Environmental and Resource Economists, vol. 5, no. 2, pp. 371-399, 2018.

[37] M. A. C. Hafstead and R. C. Williams III, "Jobs and environmental regulation," Environmental and Energy Policy and the Economy, vol. 1, no. 1, pp. 192-240, 2020.

[38] M. Casari and L. Luini, "Cooperation under alternative punishment institutions: an experiment," Journal of Economic Behavior \& Organization, vol. 71, no. 2, pp. 273-282, 2009.

[39] U. Triebswetter and J. Wackerbauer, "Integrated environmental product innovation and impacts on company competitiveness: a case study of the automotive industry in the region of Munich," European Environment, vol. 18, no. 1, pp. 30-44, 2008.

[40] C. Hao, Q. Du, Y. Huang, L. Shao, and Y. Yan, "Evolutionary game analysis on knowledge-sharing behavior in the construction supply chain," Sustainability, vol. 11, no. 19, p. 5319, 2019.

[41] M. L. Xu, X. Z. Nie, and H. Y. Jian, "Pricing decision of dualchannel supply chain with risk preference," Control and Decision, vol. 31, no. 1, pp. 91-98, 2016.

[42] M. Perc and A. Szolnoki, "Coevolutionary games-a mini review," BioSystems, vol. 99, no. 2, pp. 109-125, 2010.

[43] Z. Wang, L. Wang, A. Szolnoki et al., "Evolutionary games on multilayer networks: a colloquium," The European Physical Journal B, vol. 88, no. 5, pp. 1-15, 2015.

[44] X. Zhao and X. Bai, "How to motivate the producers' green innovation in WEEE recycling in China?-an analysis based on evolutionary game theory," Waste Management, vol. 122, pp. 26-35, 2021. 
[45] W. Chen and Z.-H. Hu, "Using evolutionary game theory to study governments and manufacturers' behavioral strategies under various carbon taxes and subsidies," Journal of Cleaner Production, vol. 201, pp. 123-141, 2018.

[46] C. F. Li, N. N. Lu, D. D. Li, and X. M. Wang, "Green innovation of enterprises: evolution of government regulation, information disclosure and investment strategy," Scientific Research, vol. 39, no. 1, pp. 180-192, 2021.

[47] C. L. Jiang, Y. Zhang, W. W. Li, and C. Wu, "Evolutionary game study on government subsidies and R\&D of new energy vehicle enterprises," Operations Research and Management, vol. 29, no. 11, pp. 22-28, 2020. 